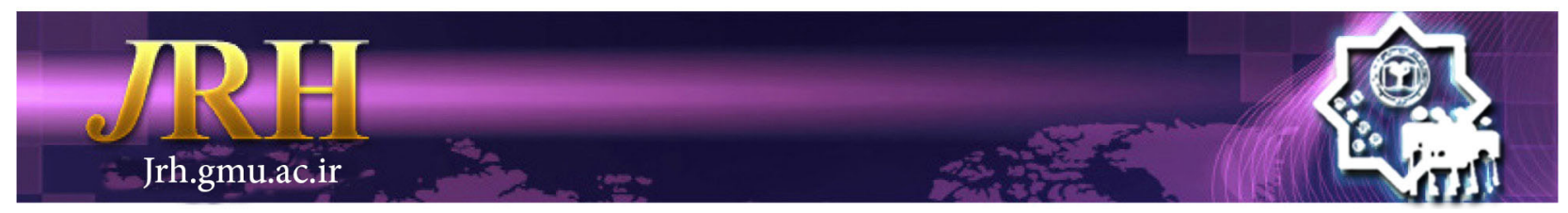

\title{
Effect of family-based intervention program on parenting skills of mothers and clinical symptoms of children with behavioral disorder
}

Sogand Ghasemzadeh ${ }^{1}$, Gholam Ali Afrooz ${ }^{1}$, Ahmad Beh-Pajooh ${ }^{1}$, Mohsen Shokoohi-Yekta ${ }^{1}$

\author{
Journal of Research \& Health \\ Social Development \& Health Promotion \\ Research Center \\ Vol. 9, No.2, Mar \& Apr 2019 \\ Pages: $156-168$ \\ DOI: 10.29252 /jrh.9.2.156 \\ Original Article
}

\begin{abstract}
1. Department of Psychology \& Education of Exceptional Children, Faculty of Psychology and Education, University of Tehran, Tehran, Iran

Correspondence to: Sogand Ghasemzadeh, Department of Psychology \& Education of Exceptional Children, Faculty of Psychology and Education, University of Tehran, Tehran, Iran

Email: S.ghasemzadeh@ut.ac.ir
\end{abstract}

Received: 12 Nov 2016

Accepted: 29 Jan 2018

How to cite this article: Ghasemzadeh S, Afrooz GhA, Beh-Pajooh A, ShokoohiYekta M. Effect of family-based intervention program on parenting skills of mothers and clinical symptoms of children with behavioral disorder. J Research \& Health2019; 9(2): 156168.

\begin{abstract}
Behavioral disorders are one of the most common psychological issues of childhood and adolescence. The aim of the present study was to examine the effect of family-based intervention program on parenting skills of mothers and clinical symptoms of children with behavioral disorder. The study was quasi-experimental research. The population all students with behavioral disorders who were studying the first to six grades in this study, sixthy students and along with their parents were selected as the main sample of the research. The research tools included Baumrind's parental style inventory and clinical symptoms checklist. The intra-family relationships promotion program was held as eight group sessions for parents, an individual family session, two phone- call sessions and an enforcement session. The research findings indicated that the family-based intervention program could improve mothers' authoritative parenting skills and also could reduce clinical symptoms of children and the results were stabled for a three-month follow-up. Therefore, family and child counselors can use this family-based intervention program to increase parenting skills of mothers and reduction clinical symptoms of children with behavioral disorder.
\end{abstract}

Keywords: Behavioral Disorder, Family, Program, Parenting

\section{Introduction}

Various studies have shown that behavioral disorders are one of the most common psychological issues of childhood and adolescence [1-3]. On the other hand, unfortunately, many children who have behavioral disorders in early adulthood not only can't pass it easily but also it continues until puberty and adulthood [4].

The prevalence of childhood behavioral disorders have been estimated about 6 to 25 percent. Of course, these reviews have mainly focused on the children who have had externalized disorders which have an extensive effect on family, teachers and 
community, and the exact prevalence rate of many internalized disorders is not available [5]. According to the latest classification in the diagnostic and statistical manual of mental disorders, fifth edition (DSM-5), children with behavioral disorders have problems in emotional and behavioral self-control. This group of children also shows common characteristics at school such as attention deficit, intransigence and defiance, obstinacy, emotional immaturity, impulsivity, aggression, anxiety, isolation, and depression [6].

Different factors are involved in the incidence of incidence of behavioral problems; even though the biological factors have an important role in the formation of behavioral disorders, the role of environmental factors especially in the formation of disorders along with this group of disorders cannot be ignored [7-9].

Factors such as physical or sexual abuse of the child, a frequent change of the school and living place, psychological pressure and stress on parents, chaotic state of the house, intense differences and family conflicts, failure of marriage, parental divorce, remarriage of a parent increase the risk of formation of emotional and behavioral problems in such children $[10,8]$.

Generally, the available research suggests that a network of factors interfere in the incidence of behavioral disorders and several factors are involved in occurrence of a behavioral disorder. Typically, behavioral disorder is a reflection of the lack of parental marital satisfaction and mental conditions, especially the mother [11]. Also, punitive and harsh parenting style which is characterized by severe physical and verbal aggression is associated with in children aggressive and non-adaptive behavior in children, and parents' psychological damage, addiction, sociopathy or negligence are associated with the incidence of behavioral disorders in children [10-14]. If the families' relation was based on logic and compassion and if there is more mutual respect among members of the family and there is no financial or occupational problems at home, so children will have fewer behavioral problems. In contrast, in families that have faced financial bankruptcy or diseases or who do not have good relations, children will certainly have more aggressive, behavioral problems $[15,16]$.

Researchers believed that there is a great difference between a child who grows in a quiet family environment full of love and a child who grows in an environment full of tension, stress, and physical punishment. Family's environment can mitigate or exacerbate unfavorable character traits of a child [17-19].

The researchers acknowledge that the symptoms of behavioral disorders in children would be reduced significantly by training of correct and effective parenting behavior [2127]. Therefore, caring for family-related issues and family-based interventions will highlight the role and importance of such studies more and more. In a study, researchers evaluated the effectiveness of the parenting program with a sample of parents of children with early onset conduct-related problems. Results showed at post intervention, participants in the parenting program group reported lower levels of child behavior problems, lower dysfunctional parenting styles, and also higher parent sense of competence compared to the control group [20]. In another study, the effectiveness of mindfulness training for children with ADHD and parallel mindful parenting training for their parents was evaluated. This study showed evidence for the effectiveness for children with ADHD and their parents [22], single case study showed parent's training was efficacious in reducing problem behaviors of ADHD children, but had no effect on hyperactivity, impulsivity \& inattention of these children [27].

Psychological interventions and family training programs are as important as the family itself. From the perspective of psychology, choosing an appropriate intervention for these children and their families has always been a challenge. Although many psychologists choose individual treatment for the problems of 
these children, the reality is that the behavioral problems of the child require different interventions for him and members of his family. According to what was said it seems like that today a perfect program is required to train parents and to promote their parenting skills, the program that can contribute to the enhancement of parental self-efficacy in parenting by improving training methods, and can ultimately lead to health and satisfying relationships for all members of the family. This study aimed to investigate the effectiveness of family-based intervention program on parenting skills of mothers and clinical symptoms of children with behavioral disorder

\section{Method}

This study was a quasi-experimental research in terms of data collection method with a four-group plan and random assignment with pretest, posttest, and follow-up. In this research the participants were randomly divided into experimental groups and control group. The random assignment process of the groups was done by online software Graph pad quick calcs. Graph pad quick calcs, a free online calculator for scientists, offers simple random allocation into equal-sized groups. The dependent variables are measured by pretest, posttest, and follow-up [28].

The population of the present research includes all students with behavioral disorders who are studying it the first to six grades in the schools of Tehran during 2013-2014 academic years and who have referred to the center of psychology and counseling services along with their parents. The inclusive criteria for the participants to participate in research and in order to homogenize the subjects in proportion with training characteristics include having the symptoms of behavioral disorder as recognized by the adolescent psychologist in the counseling center, 7-12-year-old children, having parent who live together, parents with at least diploma, participants' interest to take part in the research based on written consent and having average or above average Intelligence Quotient (IQ) for children (90 and more). The exclusion criteria for participants in the study are receiving another psychological intervention for the child during The research, beginning pharmacotherapy or changing the type or dose of medication for psychological problems of the child during one month before the intervention, comorbidity with learning disorders, receiving other psychological intervention for parents during the research, acute or chronic physical illness of father, mother, and child, and experiencing the same course by parents. The research sample was selected based on purposeful selection sampling. The sample size was calculated according to the cohen sample size formula and power was considered (0.80). The formula was calculated at the error level of $\alpha=\% 5$ and was 1.96 and The error value $E$ was considered 0.5. Finally, in this study, 60 students of elementary schools with behavioral disorder who referred to the center of psychology and counseling with their parents were selected as the main sample of the research by using purposeful selection sampling and with regard to the research inclusive and exclusive criteria. Then they were randomly divided into four equal groups of 15 participants including children and their parents as the following: First experimental group: participating in family-based intervention program. Second experimental group: taking medicine. Third experimental group: participating in familybased intervention program and taking medicine simultaneously. Control group: not receiving any intervention

In order to collect research information and data three tools were used as follows: the first one is demographic and background characteristics. demographic characteristics of participants includes gender, age, school grade, school place, physical health and psychiatric diagnosis for the child, as well as gender, physical, educational, occupational, and economic conditions for parents and the number of children in family were assessed by the researcher during the initial interview. The second one is Baumrind's parental style Inventory. It is adapted based on permissive, despotic, and authoritative behavioral pattern. This inventory consists of 30 items. 10 items 
are related to permissive or lenient method of child parenting, 10 items to despotic method, and other 10 items to authoritative method of child parenting. Parents determine their own ideas according to Liker's five-point scale. By studying each item in this inventory, participants specify their own ideas by $\mathrm{X}$ mark in one 5-point scale which is scored from 0 to $4(0=$ completely disagree, $4=$ completely agree). By adding up the scores three separate scores are obtained for each subject in permissive, despotic, and authoritative methods. The validity of the inventory has been evaluated by Esfandiari [21], and researches have reported acceptable validity and reliability for this inventory. Esfandiari did a research and asked 10 psychological and psychiatric experts to determine the validity of each question of the inventory, the results showed that the questionnaire had face validity. In order to determine the reliability of this inventory, he asked 12 mothers in the studied population to complete the inventory. After one week the inventory was completed by the same subjects. The inventory reliability was 0.69 for the permissive method, 0.77 for the despotic method, and 0.73 for the authoritative method [21]. In this study, Cronbach's alpha was calculated 0.71 for the permissive method, 0.73 for the despotic method, and 0.75 for the authoritative method. And the third one is the Child Symptom Inventory (CSI4). It is the screening tool for the most common mental disorders of children. It is a behavior rating scale that was designed in 1984 for the first time by Sprafkin \& Gadow based on DSM-III classification in order to screen 18 behavioral and emotional disorders in 5-12 -year-old children. Then, in 1987 CSI3R form was built after DSM-III classification and in 1994 it was slightly revised by the fourth edition of DSM-IV and was published as CSI-4. Like previous forms, this questionnaire has two parent and teacher forms. Parents form includes 112 questions that are set to screen 18 behavioral and emotional disorders and teacher form which contains information about schooling environment and educational performance includes 77 questions that are designed to screen 13 behavioral and emotional disorders. In this research only the questions associated with three disorders-attention deficit, hyperactivity and oppositional defiant, and parent behavior form- were applied. This inventory has been evaluated in several studies and its reliability, validity, sensitivity, characteristics and cut-off point have been calculated. In a study conducted by Sprafkin \& Gadow the reliability of the inventory for 36 children with behavioral and emotional disorders was assessed through retest and within 6-week interval for attention deficit disorder along with hyperactivity, defiant-disobedience disorder, and behavior disorder with and without aggression, respectively, and it ranged from 0.7 to 0.89 . The validity of the questionnaire has been tested by Mohammad-Esmaeil [30] in Iran and researches have reported acceptable validity and reliability for the questionnaire. Mohammad-Esmaeil reported the reliability of the whole test between 0.29 (social phobia) to 0.81 (ADHD). In this study, Cronbach's alpha was calculated 0.79 for Hyperactivity, for Attention Deficit 0.78 , for oppositional defiant 0.69 , and 0.74 for behaviour problems.

At first, 60 children with behavioral disorder along with their mothers and fathers were randomly divided into four groups and the pretest tools were administered for all four groups. Participants completed pretest questionnaires and demographic profile form. Experimental group participated in training program, but the control group received no training (Control group participants would receive training program after intervention).

According to the research output criteria only the subjects entered the research had not begun pharmacotherapy themselves or their children one month before the beginning of positive parenting program or the type or dose of their medicine or their children's medicine had not changed. This procedure included 4 public and group sessions of 180 minutes each with simultaneous presence of father and mother, then four group sessions for mothers, one private session for each family with the presence of the afflicted child for 60 minutes and then two sessions of phone calls for 15 to 
30 minutes. Two month after the end of training session, a 90-minute reinforcement meeting was also held to investigate the potential problems. Thus, the eight-session group meetings (one day a week twice a day, and each session 90 minutes) were held in person under training course as group cognitive-behavioral method. After the end of training course, the posttests were administered at the same time by the researcher assistants. Three months after the end of training session all the participants responded to the follow-up questionnaires individually.

It is worth noting that the educational content of the program has concentrated on the following general objectives; introduction to behavioral disorders, causes, interventions; familiarity with strategies to reduce the remaining causes of behavioral disorders; improving communication methods and interpersonal relationships of parents with each other, improving parentchild communication methods, improving communication methods and interpersonal relationships between family members: brothers and sisters, etc training the management of children's challenging behaviors.

Since in the current study, the researchers wanted to compare the four groups based on the means of more than one dependent variable by eliminating the initial differences between the groups, the type of analysis that is used must be multivariate analysis of covariance (MANCOVA). On the other hand, since the data are collected at different time intervals of pretest, posttest and follow-up and from a fixed set of individuals, the present research plan is the repeated measure (RM) one. It should be noted that before undertaking any statistical analysis, data screening was conducted in the level of items and subscales' scores in order to identify outliers and the data outside the scope. This study showed the presence of no with such conditions among the data. Therefore, that makes it possible to achieve these two purposes simultaneously is the multivariate analysis of covariance with repeated measure. The assumption of normal distribution for all dependent variables checked by with shapiro-wilk test in groups and phases. (SPSS-24) $(\mathrm{p}>0.05)$.

\section{Results}

Table 1 includes the mean of three experimental groups and the control group in the sub-scales of Baumrind's parental style in the pretest, posttest, follow-upstages and the combined score of posttest and followup stages. These findings suggest an average increase in authoritative and permissive parenting subscales and parenting subscale decrease in experimental groups after training course (posttest and follow-up phases). In other words, after experiencing intervention, experimental groups have demonstrated more appropriate ways of parenting skills. However, the control group does not show any significant changes in nearly all components between pretest and posttest phases.

Table 2 includes the mean of three experimental groups and the control group in the subscales of children clinical symptoms index in the pretest, posttest, follow-up stages and the combined score of posttest and followup stages. These findings indicate an average decrease in coping behavior subscales and behavior problems in experimental groups after training course (posttest and followup phases) while the control group doesn't show special changes in these subscales. In other words, after experiencing intervention, children and parents in experimental groups have reported fewer problems in their children. While in hyperactivity and attention deficit subscales the intervention and control groups was not any changes in the posttest, the medicine plus intervention group and pharmacotherapy group display significant decrease of scores.

In this section the results of testing hypotheses and making judgments about acceptance and rejection of hypotheses have been proposed. The value of Shapiro-Wilk none of the dependent variables was significant $(p>0.05)$. This indicates the normal distribution of dependent variables. On the other hand, lack of linear relationship between covariate and dependent variables could be acceptable. also Pearson's correlations indicate an acceptable relationship between dependent variables (Table 3 ). 
Table 1 Summary of descriptive findings of the sample group in the subscales of Baumrind parenting style

\begin{tabular}{|c|c|c|c|c|c|c|c|c|}
\hline Subscale & Group & Phase & Mean & $\mathrm{SD}$ & Group & Phase & Mean & $\mathrm{SD}$ \\
\hline \multirow{8}{*}{$\begin{array}{l}\text { Permissive } \\
\text { parenting }\end{array}$} & \multirow{4}{*}{ Intervention } & Pretest & 12.46 & 11.89 & \multirow{4}{*}{$\begin{array}{l}\text { Medicine+ } \\
\text { intervention }\end{array}$} & Pretest & 12.64 & 12.53 \\
\hline & & Posttest & 27.62 & 5.58 & & Posttest & 8.73 & 2.28 \\
\hline & & Follow-up & 27.69 & 5.31 & & Follow-up & 5.36 & 3.3 \\
\hline & & Combined & 55.31 & 10.77 & & Combined & 14.09 & 5.34 \\
\hline & \multirow{4}{*}{ Pharmacotherapy } & Pretest & 14.58 & 11.87 & \multirow{4}{*}{ Control } & Pretest & 17.82 & 10.76 \\
\hline & & Posttest & 17.67 & 3.96 & & Posttest & 16.64 & 9.45 \\
\hline & & Follow-up & 18 & 4.53 & & Follow-up & 16.27 & 9.31 \\
\hline & & Combined & 35.67 & 8.46 & & Combined & 32.91 & 18.75 \\
\hline \multirow{8}{*}{$\begin{array}{l}\text { Despotic } \\
\text { parenting }\end{array}$} & \multirow{4}{*}{ Intervention } & Pretest & 25.08 & 12.88 & \multirow{4}{*}{$\begin{array}{l}\text { Medicine + } \\
\text { intervention }\end{array}$} & Pretest & 28.64 & 11.71 \\
\hline & & Posttest & 9.08 & 4.07 & & Posttest & 7 & 3.32 \\
\hline & & Follow-up & 8.92 & 3.93 & & Follow-up & 4.18 & 3.37 \\
\hline & & Combined & 18 & 7.96 & & Combined & 11.18 & 6.4 \\
\hline & \multirow{4}{*}{ Pharmacotherapy } & Pretest & 27.33 & 11.66 & \multirow{4}{*}{ Control } & Pretest & 21.73 & 10.97 \\
\hline & & Posttest & 15.17 & 2.4 & & Posttest & 22.27 & 12.04 \\
\hline & & Follow-up & 15.42 & 2.54 & & Follow-up & 22 & 12.04 \\
\hline & & Combined & 30.58 & 4.8 & & Combined & 44.27 & 24.07 \\
\hline \multirow{8}{*}{$\begin{array}{c}\text { Authoritative } \\
\text { parenting }\end{array}$} & \multirow{4}{*}{ Intervention } & Pretest & 10.15 & 4.16 & \multirow{4}{*}{$\begin{array}{l}\text { Medicine + } \\
\text { intervention }\end{array}$} & Pretest & 9.27 & 8.14 \\
\hline & & Posttest & 24.46 & 14.95 & & Posttest & 35.82 & 1.66 \\
\hline & & Follow-up & 24.38 & 15.03 & & Follow-up & 38.42 & 1.17 \\
\hline & & Combined & 48.85 & 29.96 & & Combined & 74.36 & 2.16 \\
\hline & \multirow{4}{*}{ Pharmacotherapy } & Pretest & 9.25 & 1.06 & \multirow{4}{*}{ Control } & Pretest & 6.18 & 2.04 \\
\hline & & Posttest & 20 & 3.46 & & Posttest & 5.73 & 2.37 \\
\hline & & Follow-up & 20.17 & 3.71 & & Follow-up & 6.09 & 2.34 \\
\hline & & Combined & 40.17 & 6.86 & & Combined & 11.82 & 4.62 \\
\hline
\end{tabular}

It is worth noting that there is no assumption of homogeneity of variance errors for the scores. However, since the size of the studied group is the same, F test will be resistant to this abuse and the results will not be affected.

The obtained results showed that there is a significant difference between the combined score profile of parenting in four groups after eliminating the pretest effect $(\mathrm{p}<0.001$, $\eta 2=0.48$, and $(\mathrm{df}=9,123)$ and (Pillai's Trace $=1.42$, and $F=12.35)$. the findings indicate that the profiles of parenting methods in the studied group are significantly different after elimination the effect of pretest. The rate of the effect of these differences was obtained to be 0.48 which is in the average range according to Cohen classification. In the continued pursuit of the results of the effect of group, in order to specify that the differences between groups can be attributed to which components differences, "between subject effect" test was taken. According to "between subject effect" test, it could be concluded that the average post-test-follow-up combined scores in 3 experimental groups and control group in all three Permissive $(p<0.001, \eta 2=0.65$, and Fdf3 $=24.87)$, Despotic $(p<0.001, \eta 2=0.49$, and $F d f 3=13.11)$ and Authoritative $(\mathrm{p}<0.001$, $\eta 2=0.66$, and $\mathrm{Fdf} 3=26.06$ ) parenting methods are significantly different. This means that at least in two groups among the four groups there is a difference in the mean score. On the other hand, the effect rate index shows that differences in permissive and authoritative parenting are more than that of despotic parenting. In other words, intervention has been more influential in these two parenting methods. Coping track to specify which groups in each model are different led to the results in Table 4. 
Family based program in behavioral disorders

Table 2 Summary of descriptive findings of the sample group in the subscales of children clinical symptoms

\begin{tabular}{|c|c|c|c|c|c|c|c|c|}
\hline Subscale & Group & Phase & Mean & SD & Group & Phase & Mean & SD \\
\hline \multirow{8}{*}{ Hyperactivity } & \multirow{4}{*}{ Intervention } & Pretest & 8.15 & 0.56 & \multirow{4}{*}{$\begin{array}{l}\text { Medicine+ } \\
\text { intervention }\end{array}$} & Pretest & 8.64 & 0.51 \\
\hline & & Posttest & 8.15 & 1.14 & & Posttest & 0.18 & 0.41 \\
\hline & & Follow-up & 7.77 & 1.09 & & Follow-up & 0.18 & 0.41 \\
\hline & & Combined & 15.92 & 1.89 & & Combined & 0.36 & 0.81 \\
\hline & \multirow{4}{*}{ Pharmacotherapy } & Pretest & 7.83 & 0.94 & \multirow{4}{*}{ Control } & Pretest & 7.91 & 1.14 \\
\hline & & Posttest & 0.08 & 0.29 & & Posttest & 8.27 & 0.65 \\
\hline & & Follow-up & 0.08 & 0.29 & & Follow-up & 8.27 & 0.65 \\
\hline & & Combined & 0.17 & 0.58 & & Combined & 16.55 & 1.29 \\
\hline \multirow{8}{*}{$\begin{array}{l}\text { Attention } \\
\text { deficit }\end{array}$} & \multirow{4}{*}{ Intervention } & Pretest & 8.08 & 1.04 & \multirow{4}{*}{$\begin{array}{l}\text { Medicine+ } \\
\text { intervention }\end{array}$} & Pretest & 8.55 & 0.69 \\
\hline & & Posttest & 8.62 & 0.51 & & Posttest & 0.36 & 0.51 \\
\hline & & Follow-up & 7.85 & 1.28 & & Follow-up & 0.36 & 0.51 \\
\hline & & Combined & 16.46 & 1.71 & & Combined & 0.73 & 1 \\
\hline & \multirow{4}{*}{ Pharmacotherapy } & Pretest & 7.58 & 1.38 & \multirow{4}{*}{ Control } & Pretest & 8.18 & 1.4 \\
\hline & & Posttest & 0.25 & 0.45 & & Posttest & 8.45 & 1.04 \\
\hline & & Follow-up & 0.25 & 0.45 & & Follow-up & 8.45 & 1.04 \\
\hline & & Combined & 0.5 & 0.91 & & Combined & 16.91 & 2.07 \\
\hline \multirow{8}{*}{$\begin{array}{c}\text { Oppositional } \\
\text { defiant }\end{array}$} & \multirow{4}{*}{ Intervention } & Pretest & 6.54 & 0.97 & \multirow{4}{*}{$\begin{array}{l}\text { Medicine+ } \\
\text { intervention }\end{array}$} & Pretest & 7.36 & 0.81 \\
\hline & & Posttest & 2.38 & 1.66 & & Posttest & 0.73 & 0.79 \\
\hline & & Follow-up & 2.69 & 1.84 & & Follow-up & 0.73 & 0.79 \\
\hline & & Combined & 5.08 & 3.43 & & Combined & 1.45 & 1.57 \\
\hline & \multirow{4}{*}{ Pharmacotherapy } & Pretest & 6.17 & 1.03 & \multirow{4}{*}{ Control } & Pretest & 6.82 & 0.75 \\
\hline & & Posttest & 1.58 & 1.17 & & Posttest & 6.18 & 1.08 \\
\hline & & Follow-up & 1.58 & 1.16 & & Follow-up & 6.18 & 1.08 \\
\hline & & Combined & 3.17 & 2.33 & & Combined & 12.36 & 2.16 \\
\hline \multirow{8}{*}{$\begin{array}{l}\text { Behaviour } \\
\text { problems }\end{array}$} & \multirow{4}{*}{ Intervention } & Pretest & 12.08 & 1.55 & \multirow{4}{*}{$\begin{array}{l}\text { Medicine+ } \\
\text { intervention }\end{array}$} & Pretest & 13.36 & 0.67 \\
\hline & & Posttest & 2 & 1.08 & & Posttest & 0.36 & 0.51 \\
\hline & & Follow-up & 3.62 & 1.32 & & Follow-up & 0.73 & 0.79 \\
\hline & & Combined & 5.62 & 1.94 & & Combined & 0.73 & 1 \\
\hline & \multirow{4}{*}{ Pharmacotherapy } & Pretest & 12.92 & 0.9 & \multirow{4}{*}{ Control } & Pretest & 12.64 & 0.92 \\
\hline & & Posttest & 2.83 & 1.03 & & Posttest & 8.27 & 0.65 \\
\hline & & Follow-up & 2.83 & 1.03 & & Follow-up & 11.55 & 1.86 \\
\hline & & Combined & 5.67 & 2.06 & & Combined & 23.27 & 3.69 \\
\hline
\end{tabular}

Table 3 Pearson correlation matrix of dependent variables

\begin{tabular}{lcccccc}
\hline Subscale & 1 & 2 & 3 & 4 & 5 & 6 \\
\hline Permissive parenting & 1 & & & & & \\
Despotic parenting & -0.21 & 1 & & & & \\
Authoritative parenting & $0.36^{*}$ & $-0.51^{* *}$ & 1 & & & \\
Hyperactivity & 0.28 & 0.33 & 0.21 & 1 & & \\
Attention deficit & $0.45^{* *}$ & 0.27 & -0.29 & 0.24 & 1 & 0.29 \\
Oppositional defiant & $0.38^{*}$ & $0.47^{* *}$ & $-0.51^{* *}$ & $0.44^{*}$ & $0.52^{* *}$ \\
Behaviour problems & $0.48^{*}$ & $0.53^{* *}$ & $-0.55^{* *}$ & 0.33 & $0.46^{* *}$ & 0.30 \\
\hline
\end{tabular}


The results in Table 4 indicate that receiver of intervention and simultaneous receiver of intervention and medicine in all parenting methods were different from the control group while pharmacotherapy group was different from the control group in terms of despotic and authoritative parenting but not in terms of permissive (lenient) parenting.

The following is reported results Bonferroni Post Hoc Test (Table 5).

\begin{tabular}{lcccc}
\multicolumn{5}{l}{ Table 4 The mean results of parenting methods in experimental and control groups } \\
\hline Groups & Index & Permissive & Despotic & Authoritative \\
\hline \multirow{3}{*}{ Intervention } & Coping strategies & 25.12 & $26.08-$ & 39.91 \\
& Standard deviation error & 5.12 & 5.61 & 7.24 \\
& Significance level & 0.001 & 0.001 & 0.001 \\
\cline { 2 - 5 } Medicine + & Coping strategies & -15.91 & -33.78 & 65.44 \\
intervention & Standard deviation error & 5.29 & 5.79 & 7.47 \\
& Significance level & 0.004 & 0.001 & 0.001 \\
\cline { 2 - 5 } Pharmacotherapy & Coping strategies & 5.19 & -13.89 & 30.85 \\
& Standard deviation error & 5.11 & 5.6 & 7.23 \\
& Significance level & 0.32 & 0.02 & 0.001 \\
\hline
\end{tabular}

Table 5 Bonferroni Post Hoc Test

\begin{tabular}{|c|c|c|c|c|c|}
\hline Measure & (I) Group & (J) Group & Mean Difference & Std. Error & Sig. \\
\hline \multirow{12}{*}{$\begin{array}{l}\text { Permissive } \\
\text { parenting }\end{array}$} & \multirow{3}{*}{ Intervention } & Medicine + intervention & $20.57^{*}$ & 2.22 & 0.001 \\
\hline & & Pharmacotherapy & $9.82^{*}$ & 2.22 & 0.001 \\
\hline & & Control & $12.45^{*}$ & 2.33 & 0.001 \\
\hline & \multirow{3}{*}{$\begin{array}{l}\text { Medicine+ } \\
\text { intervention }\end{array}$} & Intervention & $-20.57^{*}$ & 2.22 & 0.001 \\
\hline & & Pharmacotherapy & $-10.75^{*}$ & 2.26 & 0.001 \\
\hline & & Control & $-8.12^{*}$ & 2.37 & 0.008 \\
\hline & \multirow{3}{*}{ Pharmacotherapy } & Intervention & $-9.82^{*}$ & 2.22 & 0.001 \\
\hline & & Medicine+ intervention & $10.75^{*}$ & 2.26 & 0.001 \\
\hline & & Control & 2.63 & 2.37 & 1.000 \\
\hline & \multirow{3}{*}{ Control } & Intervention & $-12.45^{*}$ & 2.33 & 0.001 \\
\hline & & Medicine+ intervention & $8.12^{*}$ & 2.37 & 0.008 \\
\hline & & Pharmacotherapy & -2.63 & 2.37 & 1.000 \\
\hline \multirow{12}{*}{$\begin{array}{l}\text { Despotic } \\
\text { parenting }\end{array}$} & \multirow{3}{*}{ Intervention } & Medicine+ intervention & 3.40 & 2.24 & 0.816 \\
\hline & & Pharmacotherapy & -6.06 & 2.24 & 0.058 \\
\hline & & Control & $-13.77^{*}$ & 2.35 & 0.001 \\
\hline & \multirow{3}{*}{$\begin{array}{l}\text { Medicine+ } \\
\text { intervention }\end{array}$} & Intervention & -3.40 & 2.24 & 0.816 \\
\hline & & Pharmacotherapy & $-9.46^{*}$ & 2.28 & 0.001 \\
\hline & & Control & $-17.17^{*}$ & 2.39 & 0.001 \\
\hline & \multirow{3}{*}{ Pharmacotherapy } & Intervention & 6.06 & 2.24 & 0.058 \\
\hline & & Medicine+ intervention & $9.46^{*}$ & 2.28 & 0.001 \\
\hline & & Control & $-7.71^{*}$ & 2.39 & 0.015 \\
\hline & \multirow{3}{*}{ Control } & Intervention & $13.77^{*}$ & 2.35 & 0.001 \\
\hline & & Medicine+ intervention & $17.17^{*}$ & 2.39 & 0.001 \\
\hline & & Pharmacotherapy & $7.71^{*}$ & 2.39 & 0.015 \\
\hline
\end{tabular}




\begin{tabular}{|c|c|c|c|c|c|}
\hline \multirow{12}{*}{$\begin{array}{c}\text { Authoritative } \\
\text { parenting }\end{array}$} & \multirow{3}{*}{ Intervention } & Medicine + intervention & $-12.66^{*}$ & 3.28 & 0.002 \\
\hline & & Pharmacotherapy & 4.34 & 3.28 & 1.000 \\
\hline & & Control & $18.57^{*}$ & 3.45 & 0.001 \\
\hline & \multirow{4}{*}{$\begin{array}{l}\text { Medicine+ } \\
\text { intervention }\end{array}$} & Intervention & $12.66^{*}$ & 3.28 & 0.002 \\
\hline & & Pharmacotherapy & $17.00^{*}$ & 3.35 & 0.001 \\
\hline & & Control & $31.23^{*}$ & 3.51 & 0.001 \\
\hline & & Intervention & -4.34 & 3.28 & 1.000 \\
\hline & \multirow[t]{3}{*}{ Pharmacotherapy } & Medicine+ intervention & $-17.00^{*}$ & 3.35 & 0.001 \\
\hline & & Control & $14.23^{*}$ & 3.51 & 0.001 \\
\hline & & Intervention & $-18.57^{*}$ & 3.45 & 0.001 \\
\hline & \multirow[t]{2}{*}{ Control } & Medicine+ intervention & $-31.23^{*}$ & 3.51 & 0.001 \\
\hline & & Pharmacotherapy & $-14.23^{*}$ & 3.51 & 0.001 \\
\hline Measure & (I) Group & (J) Group & Mean Difference & Std. Error & Sig. \\
\hline \multirow{12}{*}{$\begin{array}{l}\text { Attention } \\
\text { deficit }\end{array}$} & \multirow{3}{*}{ Intervention } & Medicine+ intervention & $7.71^{*}$ & 0.26 & 0.001 \\
\hline & & Pharmacotherapy & $7.88^{*}$ & 0.26 & 0.001 \\
\hline & & Control & -0.34 & 0.27 & 1.000 \\
\hline & \multirow{3}{*}{$\begin{array}{l}\text { Medicine+ } \\
\text { intervention }\end{array}$} & Intervention & $-7.71^{*}$ & 0.26 & 0.001 \\
\hline & & Pharmacotherapy & 0.17 & 0.26 & 1.000 \\
\hline & & Control & $-8.05^{*}$ & 0.28 & 0.001 \\
\hline & \multirow{3}{*}{ Pharmacotherapy } & Intervention & $-7.88^{*}$ & 0.26 & 0.001 \\
\hline & & Medicine + intervention & -0.17 & 0.26 & 1.000 \\
\hline & & Control & $-8.22^{*}$ & 0.28 & 0.001 \\
\hline & \multirow{3}{*}{ Control } & Intervention & 0.34 & 0.27 & 1.000 \\
\hline & & Medicine + intervention & $8.05^{*}$ & 0.28 & 0.001 \\
\hline & & Pharmacotherapy & $8.22^{*}$ & 0.28 & 0.001 \\
\hline \multirow{12}{*}{ Hyperactivity } & \multirow{3}{*}{ Intervention } & Medicine+ intervention & $7.90^{*}$ & 0.30 & 0.001 \\
\hline & & Pharmacotherapy & $7.98^{*}$ & 0.30 & 0.001 \\
\hline & & Control & -0.17 & 0.32 & 1.000 \\
\hline & \multirow{3}{*}{$\begin{array}{l}\text { Medicine+ } \\
\text { intervention }\end{array}$} & Intervention & $-7.90^{*}$ & 0.30 & 0.001 \\
\hline & & Pharmacotherapy & 0.08 & 0.31 & 1.000 \\
\hline & & Control & $-8.07^{*}$ & 0.32 & 0.001 \\
\hline & \multirow{3}{*}{ Pharmacotherapy } & Intervention & $-7.98^{*}$ & 0.30 & 0.001 \\
\hline & & Medicine + intervention & -0.08 & 0.31 & 1.000 \\
\hline & & Control & $-8.15^{*}$ & 0.32 & 0.001 \\
\hline & \multirow{3}{*}{ Control } & Intervention & 0.17 & 0.32 & 1.000 \\
\hline & & Medicine + intervention & $8.07^{*}$ & 0.32 & 0.001 \\
\hline & & Pharmacotherapy & $8.15^{*}$ & 0.32 & 0.001 \\
\hline
\end{tabular}




\begin{tabular}{|c|c|c|c|c|c|}
\hline \multirow{12}{*}{$\begin{array}{l}\text { Oppositional } \\
\text { defiant }\end{array}$} & \multirow{3}{*}{ Intervention } & Medicine + intervention & $1.87^{*}$ & 0.50 & 0.003 \\
\hline & & Pharmacotherapy & 0.96 & 0.50 & 0.384 \\
\hline & & Control & $-3.56^{*}$ & 0.53 & 0.001 \\
\hline & \multirow{3}{*}{$\begin{array}{l}\text { Medicine+ } \\
\text { intervention }\end{array}$} & Intervention & $-1.87^{*}$ & 0.50 & 0.003 \\
\hline & & Pharmacotherapy & -0.92 & 0.51 & 0.484 \\
\hline & & Control & $-5.43^{*}$ & 0.54 & 0.001 \\
\hline & \multirow{3}{*}{ Pharmacotherapy } & Intervention & -0.96 & 0.50 & 0.384 \\
\hline & & Medicine + intervention & 0.92 & 0.51 & 0.484 \\
\hline & & Control & $-4.52^{*}$ & 0.54 & 0.001 \\
\hline & \multirow{3}{*}{ Control } & Intervention & $3.56^{*}$ & 0.53 & 0.001 \\
\hline & & Medicine + intervention & $5.43^{*}$ & 0.54 & 0.001 \\
\hline & & Pharmacotherapy & $4.52^{*}$ & 0.54 & 0.001 \\
\hline \multirow{12}{*}{$\begin{array}{l}\text { Behaviour } \\
\text { problems }\end{array}$} & \multirow{3}{*}{ Intervention } & Medicine+ intervention & $1.42^{*}$ & 0.48 & 0.033 \\
\hline & & Pharmacotherapy & -0.83 & 0.48 & 0.557 \\
\hline & & Control & $-9.50^{*}$ & 0.51 & 0.001 \\
\hline & \multirow{3}{*}{$\begin{array}{l}\text { Medicine+ } \\
\text { intervention }\end{array}$} & Intervention & $-1.42^{*}$ & 0.48 & 0.033 \\
\hline & & Pharmacotherapy & $-2.25^{*}$ & 0.49 & 0.001 \\
\hline & & Control & $-10.92^{*}$ & 0.52 & 0.001 \\
\hline & \multirow{3}{*}{ Pharmacotherapy } & Intervention & 0.83 & 0.48 & 0.557 \\
\hline & & Medicine + intervention & $2.25^{*}$ & 0.49 & 0.001 \\
\hline & & Control & $-8.67^{*}$ & 0.52 & 0.001 \\
\hline & \multirow{3}{*}{ Control } & Intervention & $9.50^{*}$ & 0.51 & 0.001 \\
\hline & & Medicine + intervention & $10.92^{*}$ & 0.52 & 0.001 \\
\hline & & Pharmacotherapy & $8.67^{*}$ & 0.52 & 0.001 \\
\hline
\end{tabular}

*. The mean difference is significant at the 0.05 level.

\section{Discussion}

According to the findings of this study, parenting method profiles of the studied groups were significantly different from each other after eliminating the pretest effect. In fact, a familybased intervention program had been able to change parents parenting style significantly after the implementation of the program. According to the obtained data, the average combined scores of posttest-follow-up in three experimental groups and control group were significantly different in all three parenting methods while the control group has not shown a significant change in almost all components between the pretest and posttest. The review of the difference between three experimental groups and the control group in parenting styles subscales indicates the increase of the mean of permissive and authoritative parenting subscales and the decrease of despotic parenting subscale in the experimental groups after the training course (posttest phase and follow-up phase. On the other hand, the index associated with the rate of effect indicates that differences in permissive and authoritative parenting are more than that of despotic parenting. In other words, intervention has been more influential in these two parenting methods. In justification of this point it should said that parents who utilize authoritative parenting style are generally friendly and receptive and let their children have freedom of action rationally and logically in their behavior. Although they are serious and firm they do not lose their control during punishment and use it as the last solution. This is the best and most favorite training model. The results of most of studies show that behavioral disorder symptoms are associated with inefficient parenting styles [10]. Therefore, equipping parents with correct parenting skills such as authoritative parenting style can largely prevent the incidence of children's behavioral problems in the future. By strengthening appropriate educational model, the present program showed that it can be applied as an 
effective intervention in this context. Almost all studies have shown that appropriate training patterns such as authoritative parenting style in families who have children with behavioral disorders and problems are very pale; instead, despotic parenting style is used as the dominant training model in most of such families $[13,14]$. Another finding of the research showed that the combined grades profile of children's clinical symptoms checklists in four groups were significantly different from each other after eliminating pretest. Moreover, according to the research findings, the mean combined score of posttest-follow-up in three experimental groups and one control group were significantly different from each other in all components of children clinical symptoms. The mean difference in three experimental groups and control group in children's clinical symptoms checklist subscales (including hyperactivity, disorder, coping behavior and defiant, and behavioraldeed problems) in pretest, posttest, follow-up phases and combined score of posttest and follow-up phases indicate that the effectiveness of promotional program of intra-family relationships on clinical symptoms of children is different in various experimental groups and control group.

This is while the control group doesn't nearly show any significant difference in any of the components during pretest and posttest phases. With regard to the results of this study, the pretest and posttest scores of two simultaneous and pharmacotherapy groups were significantly different in all components of child clinical symptoms index with the control group, but the improving group was significantly different from the control group just in two components of coping behavior and disobedience as well as behavior-deed problems. Therefore, it can be concluded that this intervention program has been able to reduce only coping behaviors and deed problems of the experimental group.

The effectiveness of positive parenting programs on treatment of behavioral disorders has also been confirmed in many previous studies [20, 22-24]. Researchers acknowledge that by training correct and effective parenting behavior, the symptoms of anti-social behavioral disorders and coping defiant behaviors in children will reduce significantly [25]. The significant decrease of clinical symptoms of children with behavioral disorders particularly in coping behaviors and deed problems after the implementation of this intervention program indicates the effectiveness of improving program of intrafamily relationships on children clinical symptoms.

In explaining the results, Bjornstand, \& Montgomery [26] showed in their study that family-based interventions without needing pharmacotherapy can contribute to the management of children behavior and dealing with distress and decrease of attention deficit disorder and children hyperactivity in families [29] also used this training course for parents of children with attention deficit and hyperactivity disorder along with oppositional defiant disorder. The results of the study indicated the reduction of hyperactivity, defiant and aggressive behaviors in children and improvement of parenting behaviors and decrease of stress in parents. In another research conducted by [27], the effect of parents training program on reduction of children behavior problems with behavioral disorder was investigated and the findings showed that the training program reduced behavioral problems such as disobedience, irritability, and short temper, quarrel and beating with others. With regard to limiting the samples used in this study in terms of age range, it is required to be cautious while generalizing the obtained results to other age groups. Moreover, this research is just a cross-sectional study which has investigated the positive effects of this program for only a period of several months. It is recommended that appropriate longitudinal studies be conducted to investigate long term effects of this intervention program and to investigate the rate of reduction of children behavioral disorders symptoms of such families during the next few years.

\section{Conclusion}

Using the results of this study can be 
recommended for child psychologists and family counselors to reduce the clinical symptoms of children with behavioral disorders and to strengthen family bonds. Therefore, family and child counselors can use this family-centered intervention program to increase parenting skills of mothers and reduction clinical symptoms of children with behavioral disorder.

\section{Acknowledgements}

The present paperis retrieved from corresponding author's $\mathrm{PhD}$ dissertation titled Designing an intra-family relationships Improvement Program and evaluating its effectiveness on parent's marital satisfaction, parenting skills and clinical symptoms of their children with behavioral disorder, defended on 15th Feb 2015 and approved by department of Psychology and Education of Exceptional Children at University of Tehran with the ID number 511088033.

\section{Contribution}

Study design: GAA, SG, AB, MS

Data collection and analysis: GAA, SG, AB, MS Manuscript preparation and editing: GAA, SG, $\mathrm{AB}, \mathrm{MS}$

\section{Conflict of Interest}

"The authors declared that they have no competing interests."

\section{Funding}

The author (s) received no financial support for the research, authorship and/or publication of this article.

\section{References}

1- Carvalho Bos S, Gomes A, Clemente V, et al. Sleep and behavioral/emotional problems in children: a populationbased study. Sleep Med2009; 10(1): 66-74.

2- Bulotsky-Shearer RJ, Fantuzzo JW, McDermott PA. Typology of emotional and behavioral adjustment for low income children: A child-centered approach. J Appl Dev Psychol2010; 31(2): 180-91.

3- Gomez R, Suhaimi AF. Incidence rates of emotional and behavioural problems in Malaysian children as measured by parent ratings of the Strengths and difficulties questionnaire. Asian J Psychiatr2013; 6(6): 528-31.

4- Gimpel GA, Peacock GG, Holland ML. Emotional and behavioral problem of young children: effective intervention in the preschool and kindergarten years. New York: Guildford press; 2003.

5- Mash EJ, Barkley RA. Child psychopathology -New York: The guild ford press based system of parenting and family support. Prev Sci2002; 3(3): 183-9.

6- Association AP. Diagnostic and statistical manual of mental disorders (DSM-5®): USA: American psychiatric pub; 2013.

7- Florian V, Findler L. Mental health and marital adaptation among mothers of children with cerebral palsy. Am J Orthopsychiatry2001; 71(3): 358-67.

8-Clark DA. Design consideration in prevention research in Dozois DJA, Dobson KS, eds. The prevention of depression and anxiety: theory, research, and practice. Washington DC: American psychological association; 2004. pp: 73-98.

9-Nelson RW, Israel AC. Behavior disorders of childhood. (5thed). New Jersey: Pearson education; 2003.

10- Sanders MR, Ralph A, Thompson R, Sofronoff K, Gariner P. Every family: A public health approach to promoting children's wellbeing, Brief report. Australia, Brisbane: University of Queesland; 2005.

11- BehPajoh A. Family and children with special needs. Tehran: Avayenoor press; 2012.

12- Fishman EA, Meyers SA. Marital satisfaction and child adjustment: Direct and mediated pathways. Contemp Fam Ther2000; 22(4): 437-52.

13- Fujiwar T, Kato N, Sanders MR. Effectiveness of group positive parenting program (triple $\mathrm{p}$ ) in changing child behavior, parenting style, and parental adjustment: An intervention study in Japan. J Child Family Stud2011; 20(6): 804-13.

14- Spijkers W, Jansen DE, De Meer G, Reijneveld SA. Effectiveness of a parenting program in a public health setting: a randomized controlled trial of the positive parenting program (Triple $\mathrm{P}$ ) level 3 versus care as usual provided by the preventive child healthcare (PCH). BMC Public Health2010; 10(1): 131.

15- Barkley RA. Defiant children: a clinician's manual for assessment and parent training. New York: Guilford press; 2013.

16- Brauner CB, Stephens CB. Estimating the prevalence of early childhood serious emotional/behavioral disorders: challenges and recommendations. Public Health Rep2006; 121(3): 303-10.

17- Abrahamse ME, Junger M, Chavannes EL, Coelman FJ, Boer F, Lindauer RJ. Parent-child interaction therapy for preschool children with disruptive behaviour problems in the Netherlands. Child Adolesc Psychiatry Ment Health2012; 6(1): 24.

18-Barnyak NCA. Qualitative study in a rural community: investigating the attitudes, beliefs, and interactions of young children and their parents regarding storybook read alouds. Early Child Educ J2011; 39(2): 149-59. 
19- Lyon AR, Budd KSA. Community mental health implementation of parent child interaction therapy (PCIT). J Child Fam Stud2010; 19(5): 654-68.

20- Leung C, Sanders, MR, Leung S, Mark R, Lau J. An outcome evaluation of the implementation of the triple p-positive parenting program in Hong Kong. Fam Process 2003; 42(2): 531-44

21- Esfandiari G. Check parenting styles of mothers and mothers of normal children with behavioral disorders and the impact of parental education on children's behavioral disorders. [Thesis]. Unpublished. Tehran: Tehran Psychiatric Institute 1995.

22- Van der Oord S, Bögels SM, Peijnenburg D. The effectiveness of mindfulness training for children with ADHD and mindful parenting for their parents. $J$ Child Fam Stud2012; 21(1): 139-47.

23- Sanders MR, Markie-Dadds C, Turner KMT, Ralph A. Using the triple $\mathrm{P}$ system of intervention to prevent behavioural problems in children and adolescents. In Barrett PA, Ollendick TH, eds. Handbook of interventions that work with children and adolescents: Prevention and treatment. Chichester, England: Wiley; 2004. pp: 489-516. 24- Sanders MR, McFarland M. Treatment of depressed mothers with disruptive children: A controlled evaluation of cognitive behavioral family intervention. Behav
Ther2000; 31(1): 89-112.

25- Chronis AM, Chacko A, Fabiano GM, Wymbs BT, Pelham WE jr. Enhancement to the behavioral parent training, Paradigm for families of children with ADHD: Review and future directions. Clin Child Fam Psycho Rev2004; 7(1): 1-27.

26- Bjornstand, G, Montgomery P. Famliy therapy for attention deficit disorder or attention deficit/ hyperactivity disorder in children and adolescents. Cochrane Database Syst Rev2005;135: 1469-93

27- Zargari Nezhad G, Yekeh Yazdandost R. Efficacy of parent's training on problem behaviors in ADHD children. Psychological Studies2007; 3(2): 29-48.

28- Tuckman BW, Harper BE. Conducting educational research. USA, Maryland: Rowman \& Littlefield publishers; 2012.

29- Danforth JS, Harvey E, Ulaszek WR, McKee TE. The outcome of group parent training for families of children with attention-deficit hyperactivity disorder and defiant/ aggressive behavior. J Behav Ther Exp Psychiatry2006; 37(3): 188-205.

30- Mohammad Esmaeel E. Adaptation and standardization of signs log CSI-Fourth Edition (CSI4). Journal of Exceptional Children (research on exceptional children)2007; 7(1): 79-96.

Copyright $\odot 2016$ ASP Ins. This open-access article is published under the terms of the Creative Commons Attribution-NonCommercial 4.0 International License which permits Share (copy and redistribute the material in any medium or format) and Adapt (remix, transform, and build upon the material) under the Attribution-NonCommercial terms. 